\title{
Plasma levels of immunoreactive atrial natriuretic hormone in patients with diabetes mellitus*
}

\author{
Joel K. Kahn, Roger J. Grekin, Yoram Shenker and Aaron I. Vinik \\ Department of Internal Medicine, Division of Endocrinology and Metabolism, Department of Surgery, \\ University of Michigan and Veterans Administration Medical Centers, Ann Arbor, Michigan, U.S.A.
}

(Received 10 June 1986; revised manuscript received 24 July 1986; accepted for publication 28 July 1986)

\begin{abstract}
Summary
In order to determine whether atrial natriuretic hormone (ANH) secretion is altered in diabetic patients with autonomic neuropathy, plasma immunoreactive ANH (IR-ANH) levels were measured in 23 patients with insulin-dependent diabetes mellitus, 12 of whom had definite cardiac autonomic neuropathy determined by noninvasive maneuvers. Levels were also measured in 31 healthy control subjects. Whereas only one of the 11 diabetics without cardiac autonomic neuropathy had elevated IR-ANH levels, four of the 12 diabetics with cardiac autonomic neuropathy had elevated IR-ANH levels ( $P=0.03$ compared to control subjects). 24-h urinary sodium excetion was not different among the groups. There was no significant correlation between IR-ANH levels and diabetes control and any of the parameters of autonomic nervous system activity nor between IR-ANH levels and plasma norepinephrine or epinephrine levels. Furthermore, no relationship was observed in the diabetic subjects between IR-ANH levels and left ventricular ejection fraction determined by radionuclide ventriculography. Thus, elevated IR-ANH levels occur with greater frequency in diabetic patients with autonomic neuropathy. These elevations do not appear to be due to alterations in dietary sodium intake or left ventricular dysfunction.
\end{abstract}

atrial natriuretic hormone; immunoreactivity; plasma levels; diabetes mellitus

\footnotetext{
* Supported by grant HL 18575 of the National Heart, Lung and Blood Institute, grant 5 M01 RR-42 from the division of Research Resources, National Institutes of Health, grant AM-20572-07 from the Michigan Diabetes Research and Training Center, and the research service of the Veterans Administration.

Address correspondence to: Aaron I. Vinik, M.D., 2922 B Taubman Health Center, University of Michigan, 1500 E. Medical Center Drive, Box 0331, Ann Arbor, MI 48109, U.S.A. Telephone (313) 936-5797.
} 


\section{Introduction}

Specific protein-containing granules have been observed in mammalian atria $[1,2]$ and the number of granules present in the heart varies with changes in vascular volume and composition [3]. These granules contain a group of vasoactive, natriuretic peptides that have been collectively termed the atrial natriuretic factor (ANF) $[4,5]$. With the recent report of measurable ANF levels in human plasma [6-8] and the description of membrane receptors for ANF in arterial smooth muscle, renal [9], and adrenal cortical tissue [10], a role for ANF as a circulating hormone seems assured. In this regard, we believe the term atrial natriuretic hormone (ANH) is more appropriate.

The mechanisms whereby ANH secretion occur are speculative. It has been suggested that increased atrial stretch may directly result in ANH secretion [11-13]. Whether neural or hormonal stimulation of ANH secretion occurs is unknown, but previous observations suggest that these mechanisms may be functioning in the regulation of ANH secretion. Areas of the cardiac atria that are very sensitive to small changes in atrial stretch are richly supplied with nerve endings from the autonomic nervous system [14]. Changes in the number of atrial granules have been observed following manipulations of autonomic nervous system activity [15,16]. Recently, adrenergic and cholinergic agonists have been shown to stimulate ANH release in vitro $[17,18]$ and in vivo [19].

A dysautonomia involving cholinergic and adrenergic systems develops in many patients with diabetes mellitus [20] and may be detected and graded by cardiovascular reflex tests $[21,22]$ and plasma catecholamine levels [23]. As part of an ongoing study on the relationship between the autonomic nervous system and cardiovascular disease in diabetes mellitus, we have characterized autonomic nervous system activity and left ventricular performance in a number of subjects with diabetes mellitus [24]. In order to investigate whether a relationship exists between ANH and autonomic nervous system activity or left ventricular performance, we have measured immunoreactive-ANH (IR-ANH) in the plasma of subjects with diabetes mellitus. We report here that IR-ANH levels are elevated among some patients with diabetes mellitus, particularly in those with autonomic neuropathy. The mechanism of release and importance of the elevated circulating hormone levels needs to be determined.

\section{Methods}

\section{Subjects}

Nineteen male and 12 female normotensive healthy volunteers, aged 19 to 39 years, consuming a regular diet were studied. Blood was drawn from the subjects in the recumbent position through a butterfly needle. A urine sample for sodium and creatinine was collected during the $24 \mathrm{~h}$ preceding the venous sampling. Due to incomplete urine collections in 6 of the control subjects, urinary data from only 25 of them were included.

Seven male and 16 female subjects, 19 to 44 years old, with insulin-dependent 
diabetes mellitus (duration 10 to 28 years) were studied in a manner similar to that of controls. Criteria for selection included a blood pressure $<140 / 90 \mathrm{~mm} \mathrm{Hg}$ without therapy, a creatinine clearance $>75 \mathrm{ml} / \mathrm{min}$ and a serum creatinine level $<1.5 \mathrm{mg} / \mathrm{dl}$, no clinical evidence of congestive heart failure (gallop rhythm, rales, neck vein distention), and no peripheral edema of any cause. All medications other than insulin were discontinued $24 \mathrm{~h}$ prior to study. All patients were in sinus rhythm.

Samples were drawn into EDTA tubes, placed on ice, and plasma was separated within 15 min of sampling. Plasma samples for IR-ANH were stored at $-70^{\circ} \mathrm{C}$.

\section{Assay methods}

Measurement of IR-ANH was performed as described by Shenker et al. [6]. Briefly, plasma was extracted through $\mathrm{C}_{18}$ cartridges (Sep-Pak; Waters Associates, Milford, MA), eluted, and air-dried overnight. Synthetic ANH standard (atriopeptin III) and antibody against 1-28 alpha human atrial natriuretic peptide were purchased from Peninsula Laboratories, Inc., (Belmont, CA), and ${ }^{125}$ I-atriopeptin III was prepared using a chloramine-T procedure. Following an $18 \mathrm{~h}$ incubation, free and bound hormone were separated using dextran charcoal. Recovery of synthetic atriopeptin III was $56.6 \pm 2.4 \%$. Plasma levels of $\mathrm{ANH}$ were calculated in pmol/l after correction for recovery. Intraassay variation was $8.5 \%$ and interassay variation was $12.6 \%$.

\section{Extent of cardiac autonomic neuropathy}

Patients were tested for cardiac autonomic neuropathy using five non-invasive indices of autonomic function $[21,22]$. The response to each test of autonomic function was graded as normal or abnormal and patients were assigned an autonomic function score from 0 to 5 based on the sum of the number of abnormal tests. A subject was classified as having definite cardiac autonomic neuropathy if two or more tests were abnormal as suggested by Ewing et al. [22]. The screen consisted of:

(1) Resting pulse. This was determined by examination of an electrocardiographic tracing after the subjects had been lying supine for $15 \mathrm{~min}$. Abnormal was defined as $\geq 100$ beats/min.

(2) Beat to beat heart rate variability. This was determined with the subject lying quietly and breathing deeply at 6 breaths per min. The difference between the minimum and maximum heart rate was determined by electrocardiographic tracings over $1 \mathrm{~min}$. Abnormal was defined as $\leq 10$ beats $/ \mathrm{min}$.

(3) Valsalva maneuver. Subjects blew into a manometer to maintain a pressure of $40 \mathrm{~mm} \mathrm{Hg}$ for $15 \mathrm{sec}$ during continuous electrocardiographic monitoring. The ratio of the longest $R-R$ interval after the maneuver to the shortest $R-R$ interval during the maneuver was calculated. Abnormal was defined as $\leq 1.10$.

(4) Heart rate response to standing. During continuous electrocardiographic monitoring, the ratio of the $\mathrm{R}-\mathrm{R}$ interval of the 30 th beat after standing compared to the $R-R$ interval at the 15 th beat (30:15 ratio) was calculated. Abnormal was defined as $\leq 1.02$.

(5) Blood pressure response to standing. The fall in systolic blood pressure after 1 min of standing was determined using cuff sphygmomanometry. Abnormal was defined as $\geq 30 \mathrm{~mm} \mathrm{Hg}$. 


\section{Equilibrium radionuclide ventriculography}

Gated blood pool scintigraphy was performed with the subjects in the supine position using the in vivo labeling method with $25 \mathrm{mCi}$ of technetium- $99 \mathrm{~m}$ pertechnetate. Imaging was accomplished using a conventional Anger camera equipped with a high sensitivity parallel-hole collimator interfaced to a dedicated minicomputer system. The left anterior oblique projection that best isolated the left ventricle was used. The data were digitized to a $64 \times 64$ pixel matrix for subsequent analysis and the cardiac cycle was formatted into 32 frames. Data acquisition was terminated after 300000 counts per frame were obtained. In our facility a normal left ventricular ejection fraction is $\geq 50 \%$.

\section{Determination of plasma catecholamines}

Blood samples were also collected after 30 min with the subject in the recumbent position. Plasma norepinephrine and epinephrine concentrations were measured in the University of Michigan Diabetes Research and Training Center Ligand Core Laboratory by the method of Peuler and Johnson [25].

\section{Statistical methods}

Data were entered into the CLINFO database of the University of Michigan Clinical Research Center. Although the data are non-gaussian, they are expressed as mean \pm S.E. for the sake of comparison. IR-ANH levels in the diabetic patients were compared to levels in the control subjects using the Wilcoxon rank sum test and Fisher's exact test. Spearman rank correlations were used to determine if a correlation existed between IR-ANH and other variables.

\section{Experimental results}

Twelve of the 23 subjects with diabetes mellitus had definite cardiac autonomic neuropathy, but did not differ from the eleven diabetics without cardiac autonomic neuropathy with regard to age, duration of diabetes or urinary sodium or creatinine (Table I). Urinary sodium in control and diabetic subjects was similar. Recumbent catecholamine levels were not significantly different between the two groups of diabetic subjects and were within the normal range [23].

IR-ANH was detectable in all plasma samples. In the healthy volunteers IR-ANH levels ranged from 1.0 to $46.0 \mathrm{pmol} / \mathrm{l}$ (Fig. 1). Among diabetic patients without cardiac autonomic neuropathy IR-ANH levels ranged from 8 to $58 \mathrm{pmol} / 1$, and in the diabetic patients with cardiac autonomic neuropathy levels ranged from 5 to 97 pmol/1. There were no significant differences between the mean values of the two patient groups and the control subjects (Table I). Five of the 23 diabetic subjects had IR-ANH levels that were more than 2 standard deviations above the mean level of the control subjects $(P=0.07)$. The clinical characteristics of the five diabetic patients with elevated IR-ANH levels are shown in Table II. Four of the 5 diabetic patients with elevated IR-ANH levels had definite cardiac autonomic neuropathy. The presence of elevated IR-ANH levels in 4 of the 12 diabetic patients with cardiac auto- 
TABLE I

Characteristics of diabetic patients and normal control subjects

\begin{tabular}{lccl}
\hline & $\begin{array}{l}\text { Diabetic subjects } \\
\text { without }{ }^{*} \text { CAN }(n=11)\end{array}$ & $\begin{array}{l}\text { Diabetic subjects } \\
\text { with CAN }(n=12)\end{array}$ & $\begin{array}{l}\text { Normal controls } \\
(n=31)\end{array}$ \\
\hline $\begin{array}{l}\text { Age (years) } \\
\text { Years diabetes }\end{array}$ & $36.1 \pm 2.6$ & $33.8 \pm 2.7$ & $25.0 \pm 1.0$ \\
$\begin{array}{l}\text { Urine sodium } \\
(\mathrm{mEq} / 24 \mathrm{~h})\end{array}$ & $18.7 \pm 1.6$ & $16.7 \pm 2.4$ & - \\
IR-ANH (pmol/l) & $153 \pm 18$ & $168 \pm 11$ & $186 \pm 17$ \\
& $17.0 \pm 4.4$ & $27.5 \pm 7.6$ & $13.1 \pm 1.6$ \\
\hline
\end{tabular}

Data are mean \pm S.E.

* CAN denotes cardiac autonomic neuropathy (see text for details).

nomic neuropathy compared to one of the 31 control subjects is significantly different ( $P=0.03$, Fisher's exact test), but is not significantly different from the presence of elevated levels in one of the 11 diabetic patients without cardiac autonomic neuropathy $(P=0.31)$ (Fig. 1). There was no correlation between IR-ANH levels and the degree of glycemic control as evaluated by $\mathrm{HbA}_{1 \mathrm{c}}$ levels.

The correlations between IR-ANH levels and either the total autonomic function score $(r=0.29)$ or the individual tests of autonomic function (data not shown) were not significant (Fig. 2A). There was no significant relationship between IR-ANH levels and either the recumbent norepinephrine $(r=-0.14)$ or epinephrine $(r=$

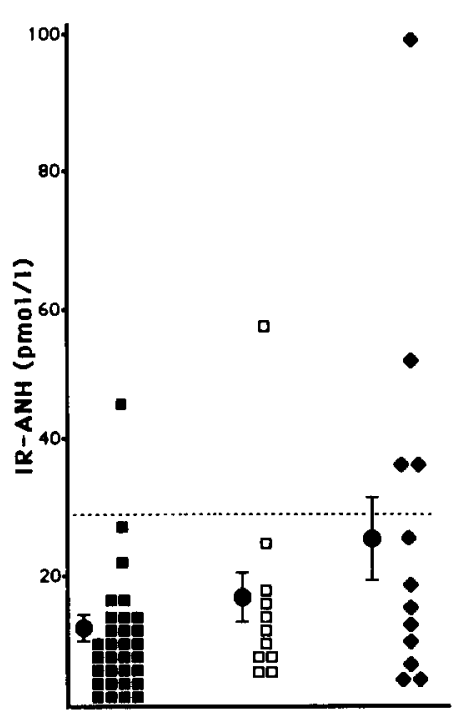

Fig. 1. Plasma levels of immunoreactive atrial natriuretic hormone (IR-ANH) in 31 control subjects (solid boxes), 11 patients with diabetes mellitus without cardiac autonomic neuropathy (open boxes) and 12 patients with diabetes mellitus and cardiac autonomic neuropathy (diamonds). Solid circles indicate mean \pm S.E. The broken line $(30.5 \mathrm{pmol} / 1)$ indicates the mean plus two standard deviations for control subjects. 


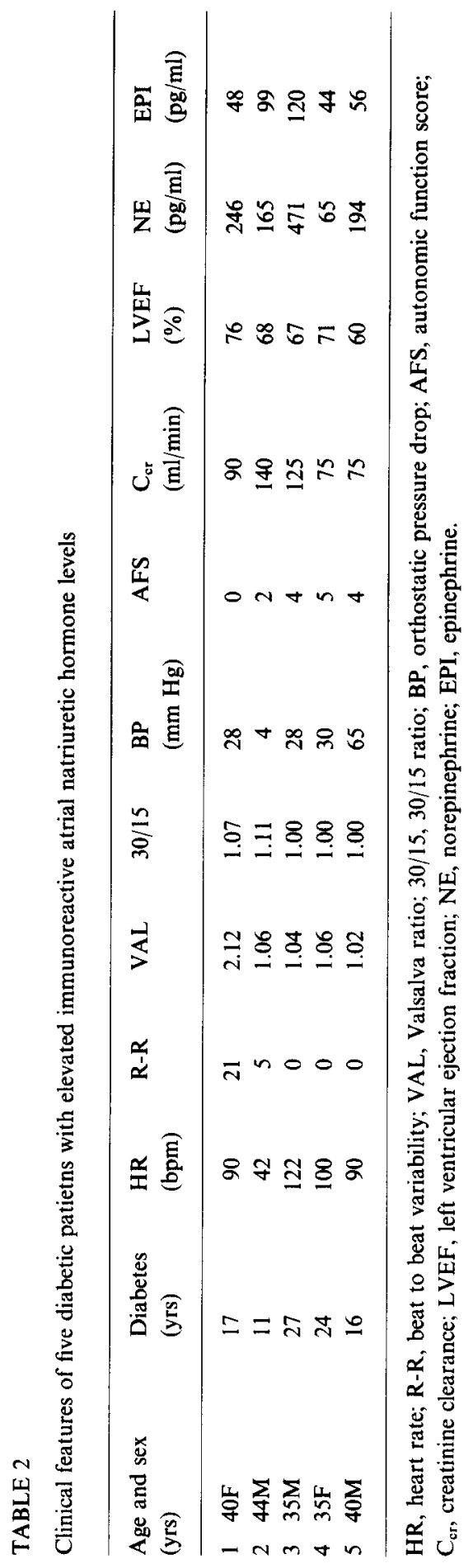



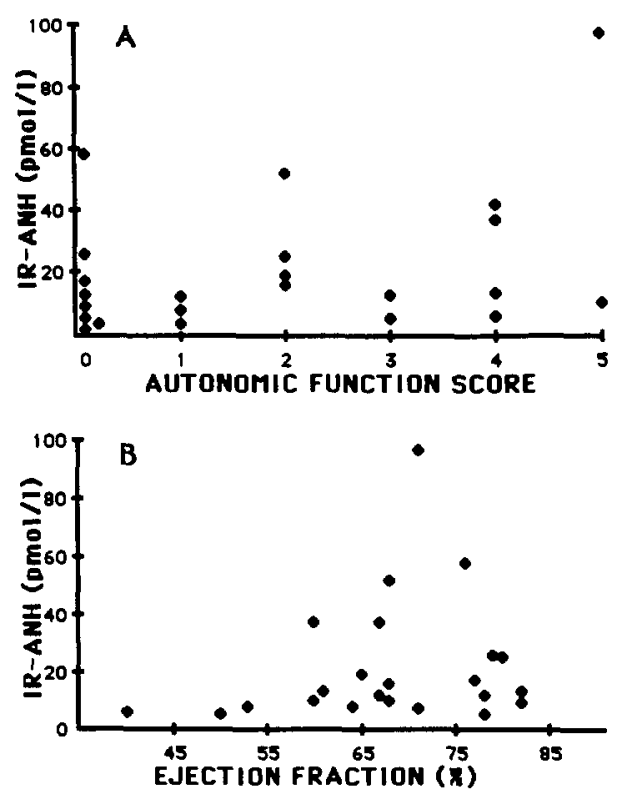

Fig. 2. (A) Scatter plot of immunoreactive atrial natriuretic hormone (IR-ANH) against the autonomic function score (see text for details) $(r=0.30, P=0.16)$. (B) Scatter plot of immunoreactive atrial natriuretic hormone (IR-ANH) against left ventricular ejection fraction (LVEF) $(r=0.22, P=0.30)$.

$-0.18)$ levels. The relationship between IR-ANH levels and left ventricular ejection fraction is shown in Fig. 2B.

\section{Discussion}

We have measured circulating IR-ANH in the plasma of 23 diabetic subjects and have observed elevated levels in five of these subjects. Factors that might result in elevated IR-ANH levels are uncertain and there is little direct data regarding physiologic regulation of ANH release. Studies demonstrating a diuresis [26] and natriuresis [27] following atrial distention led to investigation of the role of atrial distention in ANH secretion. Using a bioassay, Dietz [11] detected increased natriuretic activity in the effluent of rat heart-lung preparations following atrial distention. Lang et al. [12] observed that atrial distention in isolated rat hearts resulted in ANH release detected by radioimmunoassay, and Ledsome et al. [13] recorded similar observations in anaesthetized dogs. Our studies [6] and others [28] have demonstrated elevated IR-ANH levels in patients with left ventricular dysfunction. The degree of IR-ANH elevation was positively correlated with the severity of the left ventricular dysfunction in both studies $[6,28]$, suggesting that the degree of atrial distention determines the ANH response in humans.

Although intracardiac pressure determinations were not performed, elevated atrial pressure is an unlikely explanation for the increased IR-ANH levels observed in this study. Patients were free of edema, jugular venous distention and congestive heart 
failure. Furthermore, 22 of the 23 subjects had normal global ventricular performance by radionuclide ventriculography and no correlation between IR-ANH and ejection fraction was present (Fig. 2). The patient with the lowest ejection fraction had an IR-ANH level in the normal range.

Although IR-ANH levels are increased by high sodium diet, it is unlikely that differences in diet were adequate to explain the observed elevations in IR-ANH as urinary sodium levels in the diabetic patients were not significantly different from those measured in controls (Table I).

Previous work supports the concept that autonomic neuronal dysfunction might result in altered ANH secretion. Reserpine reduces atrial granularity [15] and betablockers can increase atrial granularity [16]. Recent investigations have demonstrated increased secretion of ANH from isolated rat atria exposed to epinephrine and acetylcholine $[17,18]$, although these results have been questioned due to the absence of appropriate controls [29]. We have demonstrated that infusions of epinephrine in six normal subjects led to significant increases in plasma IR-ANH levels [19]. The plasma levels of epinephrine achieved during these infusions were much higher than those measured in the present study (Table II). The mechanism whereby catecholamines alter ANH secretion is unknown.

Although cardiac autonomic neuropathy was detected in most of the patients with elevated IR-ANH levels, no significant relationship between IR-ANH levels and parameters of autonomic function could be established. It may be that there is no association between autonomic dysfunction and IR-ANH, implying that other factors, such as unrecognized atrial pressure elevations, altered $\mathrm{ANH}$ metabolism, or alterations in as yet unknown modulators of ANH release, were operative in our patients. Alternatively, the autonomic nervous system may indeed play a role in ANH regulation but the measurements of autonomic function currently used, such as cardiovascular reflex tests and plasma catecholamine levels, may not be adequately sensitive to establish such a relationship. Furthermore, the study comprises a small group of subjects and the findings may not be universally applicable. Further study will be required in a larger group of subjects to determine whether more precise measurements of autonomic function such as transmyocardial catecholamine gradients or direct sympathetic nerve fiber recordings can establish a relationship.

The clinical manifestations of elevated ANH levels in patients with diabetes mellitus, if any, are unknown, It is interesting to speculate however as to whether the glomerular hyperfiltration characteristic of Type I patients $[30,31]$ might be due in part to $\mathrm{ANH}$, since ANH results in marked increases in glomerular filtration rates when administered to animals [5]. Glucagon and growth hormone have been implicated in the genesis of hyperfiltration [32,33], but the diurnal plasma concentrations of these two hormones were not found to be higher in diabetic patients with hyperfiltration than in those with normal glomerular filtration rate [34] and other factors may be influential. Although we did not observe increased glomerular filtration rates in all of the long-term diabetic patients with elevated ANH levels (Table II), further studies in early insulin-dependent diabetic patients will be required to explore this interesting possibility. 


\section{Acknowledgements}

The authors would like to thank Martha Funnell for performing the autonomic screening, Richard Sider for his assistance with performing the IR-ANH assay, Steven Schmaltz for help with computer and statistical analysis using the CLINFO system, Mary Harper for her editorial assistance, and Caprice C. Wolfer for her secretarial assistance.

\section{References}

1 Jamieson, J.D. and Palade, G.E., Specific granules in atrial muscles, J. Cell Biol., 23 (1964) 151-172.

2 Huet, M. and Cantin, M., Ultrastructural cytochemistry of atrial muscle cells. II. Characterization of the protein content of specific granules, Lab. Invest. 30 (1974) 525-532.

3 de Bold, A.J., Heart atria granularity: effect of changes in water-electrolyte balance, Proc. Soc. Exp. Biol. Med., 161 (1979) 508-511.

4 Flynn, T. G., de Bold, M.L. and de Bold, A. J., The amino acid sequence of an atrial peptide with potent diuretic and natriuretic properties, Biochem. Biophys. Res. Commun., 117 (1983) 859-865.

5 Palluk, R., Gaida, W. and Hoefke, W., Minireview. Atrial natriuretic factor, Life Sci., 36 (1985) 1415-1425.

6 Shenker, Y., Sider, R. S., Ostafin, E. A. and Grekin, R. J., Plasma levels of immunoreactive atrial natriuretic factor in healthy subjects and in patients with edema, J. Clin. Invest., 76 (1985) 1684-1687.

7 Gutkowska, J., Bourassa, M., Roy, D., Thibault, G., Garcia, R., Cantin, M. and Genest, J. Immunoreactive atrial natriuretic factor (IR-ANF) in human plasma, Biochem. Biophys. Res. Commun., 129 (1985) 439-446.

8 Larose, P., Meloche, S., deSouich, P., De Lean, A. and Ong, H. Radioimmunoassay of atrial natriuretic factor: human plasma levels, Biochem. Biophys. Res. Commun., 130 (1985) 553-558.

9 Napier, M.A., Vandlen, R.L., Albers-Schonberg, G., Nutt, R.F., Brady, S. Lyle, T., Winquist, R., Faison, E.P., Heinel, L.A. and Blaine, E.H., Specific membrane receptors for atrial natriuretic factor in renal and vascular tissues, Proc. Natl. Acad. Sci. USA, 81 (1984) 5946-5950.

10 De Lean, A., Gutkowska, J., McNicoll, N., Schiller, P.W., Cantin, M. and Genest, J., Characterization of specific receptors for atrial natriuretic factor in bovine adrenal zona glomerulosa, Life Sci., 35 (1984) 2311-2318.

11 Dietz, J.R., Release of natriuretic factor from rat heart-lung preparation by atrial distention, Am. J. Physiol., 247 (1984) R1093-1096.

12 Lang, R.E., Thalken, H., Ganten, D., Luft, F.C., Ruskoaho, H. and Unger, R.H., Atrial natriuretic factor as a circulating hormone stimulated by volume loading, Nature, 314 (1985) 266-266.

13 Ledsome, J.R., Wilson, N., Courneya, C. A. and Rankin, A. J., Release of atrial natriuretic peptide by atrial distention, Can. J. Physiol. Pharmacol., 63 (1985) 739-742.

14 Paintal, A.S., A study of right and left atrial receptors. J. Physiol. (London), 120 (1953) 596-610.

15 Otsuka, N., Okamoto, H. and Tomisawa, M., Electron and fluorescence microscopic study of specific granules in rat atrial muscles, Arch. Histol. Jpn., 30 (1969) 367-378.

16 Okamoto, H., An electronmicroscopic study of the specific granules in atrial muscle cells upon administration of agents affecting autonomic nerves, Arch. Histol. Jpn., 30 (1969) 467.

17 Sonnenberg, H. and Veress, A. T., Cellular mechanisms of release of atrial natriuretic factor, Biochem. Biophys. Res. Commun., 124 (1984) 443-449.

18 Sonnenberg, H., Krebs, R.F. and Veress, A.T., Release of atrial natriuretic factor from isolated rat heart atria, I.R.C.S. Med. Sci., 12 (1985) 983-984.

19 Sanfield, J. A., Shenker, Y., Grekin, R. J. and Rosen, S. G., Epinephrine infusion increases immunoreactive atrial natriuretic factor levels in humans (Abstract), Clin. Res., 33 (1985) 828A.

20 Rundles, R.W., Diabetic neuropathy, Medicine, 24 (1965) 110-160. 
21 Jackson, W.P.U., Vinik, A.I. and Sive, A., Diabetic neuropathy, S. African J. Hosp. Med., July (1978) 196-205.

22 Ewing, D.J., Martyn, C.N., Young, R.J. and Clarke, B.F., The value of cardiovascular autonomic function test: 10 years experience in diabetes, Diabetes Care, 8 (1985) 491-496.

23 Christensen, N.J., Catecholamines and diabetes mellitus, Diabetologia, 16 (1979) 211-224.

24 Kahn, J.K., Zola, B., Juni, J. and Vinik, A.I., Cardiac autonomic neuropathy cases left ventricular dysfunction in diabetes mellitus (Abstract), Clin. Res., 33 (1985) 198A.

25 Peuler, J.D. and Johnson, G.A., Simultaneous single isotope radioenzymatic assay of plasma norepinephrine, epinephrine and dopamine, Life Sci., 21 (1976) 625-636.

26 Henry, J.P., Gauer, D.H. and Reeves, J.L., Evidence of the atrial location of receptors influencing urine flow. Circ. Res., 5 (1956) 85-90.

27 Linden, R.J., Atrial reflexes and renal function. Am. J. Cardiol., 44 (1979) 879-883.

28 Tikkanen, I., Metsarinne, K., Fyhrquist, A. and Leidenius, R., Plasma atrial natriuretic peptide in cardiac disease and during infusion in healthy volunteers, Lancet, 2 (1985) 66-69.

29 Needleman, P., Adams, S.P., Cole, B.R., Currie, M.G., Geller, D.M., Michener, M.L., Saper, C.B., Schwartz, D. and Standaert, D.G., Atriopeptins as cardiac hormones, Hypertension, 7 (1985) 469482.

30 Mogensen, C.E. and Andersen, M.J.F., Increased size and glomerular filtration rate in early juvenile diabetes, Diabetes, 22 (1973) 706-712.

31 Wiseman, M.J., Saunders, A.J., Keen, H. and Viberti, G.C., Effect of blood glucose control on increased glumerular filtration rate and kidney size in insulin dependent diabetes, N. Engl. J. Med., 312 (1985) 617-621.

32 Parving, H.H., Christiansen, J.S., Noer, I., Tronier, B. and Mogensen, C. E., The effect of glucagon infusion on kidney function in short-term insulin-dependent juvenile diabetics, Diabetologia, 19 (1980) 350-354.

33 Christiansen, J.S., Gammelgaard, J., Frandsen, M., Orskov, H. and Parving, H.H., Kidney function and size in Type 1 (insulin-dependent) diabetic patients before and during growth hormone administration for one week, Diabetologia, 22 (1982) 333-339.

34 Wiseman, M.J., Viberti, G.C., Redmond, S. and Keen, H., Plasma glucose, glucagon and growth hormone profiles in insulin-dependent diabetics with elevated glomerular filtration rate (abstract), Eur. J. Clin. Invest., 14, 2: Part 2 (1984) 24. 